\title{
Prevalence of Autism Spectrum Disorders (ASD) and its association with medical issues and behaviour problems among Children with Intellectual Disability (ID).
}

\author{
Shankar Kumar ${ }^{1}$, Sneha Venkatakrishna ${ }^{2}$, Archana Gopal ${ }^{3}$, Sushmitha Kota ${ }^{4}$ \\ ${ }^{1}$ Assistant Professor, Department of Psychiatry, Bangalore Medical College and Research Institute. \\ ${ }^{2}$ Department of Psychiatry, Bangalore Medical College and Research Institute. \\ ${ }^{3}$ Senior Resident, Department of Psychiatry, Bangalore Medical College and Research Institute. \\ ${ }^{4}$ Department of Psychiatry, Bangalore Medical College and Research Institute. \\ Corresponding author: Shankar Kumar \\ Email: shankarkjs@gmail.com
}

\begin{abstract}
Background: The presence or absence of Intellectual Disability(ID) has been recognized as one of the strongest determinant of outcomes for individuals with Autism Spectrum Disorder(ASD). Behavioural problems which are commonly reported in autism may be related to core features of autism, comorbid diagnoses or symptoms. There is paucity of Indian studies on prevalence of ASD among children diagnosed with ID and also the prevalence of behaviour problems in this population. This study was conducted with the objectives to assess the prevalence of ASD in the intellectually disabled, as well as the associated comorbidity patterns.

Methodology: It was a cross sectional study including 122 children with mild/moderate Intellectual Disability between 6 to 18 years. Indian Scale for Assessment of Autism(ISAA), Behaviour Problems Inventory(BPI) was administered and questions were asked to know medical symptoms.

Results: Prevalence of co-morbid ASD in children with ID was with $16.39 \%$. Children with ASD had higher behavioural problems $(p=0.001)$, higher medical complaints like GI symptoms (constipation $p=0.001$, bloating $p=0.03$, abdominal pain $p=0.03)$ and seizure $(p=0.002)$. Behaviour problems were higher in children with more severe autism scores.

Conclusion: There is a notable prevalence of ASD in children with ID. These children tend to have higher behavioural problems and co-morbid medical issues which needs clinical attention for better overall management of these children.
\end{abstract}

Keywords: Intellectual disability, Autism spectrum disorder, epilepsy, behaviour problems, medical comorbidities

$$
\text { (Paper received }-13^{\text {th }} \text { December 2020, Peer review completed }-5^{\text {th }} \text { February 2021) }
$$

(Accepted $-26^{\text {th }}$ February 2021)

\section{INTRODUCTION}

Autism spectrum disorders (ASD) are characterised by persistent deficits in social communication with restricted patterns of behaviour, interests or activities [1]. Intellectual Disability (ID), according to the American Association of Intellectual and Developmental Disabilities (AAIDD), is marked by significant limitations (two standard deviations below average) in both intellectual functioning and adaptive behaviours, as measured by standardized assessments. The presence or absence of ID has been recognized as one of the strongest determinants of outcomes for individuals with ASD [2]. According to previous studies, one in four individuals with ID is diagnosed with ASD [3-4]. Behavioural problems which are commonly reported in autism may be related to core features of autism, comorbid diagnoses or symptoms 
(e.g. agression, disruption, hyperactivity, self-injury), or sensory abnormalities. Co-morbid medical conditions like seizures, immune system dysregulation, gastrointestinal symptoms, feeding difficulties (e.g., refusal, selectivity, sensitivity to textures), and sleep disruption can also occur in autism.

Estimated rates of ASD-ID comorbidity vary between 25 and $70 \%$ according to various previous studies [514]. Estimates of prevalence range from 1-2 per 1000, and about 1 in 250 in India [15] with reports of increasing incidence since the past few decades [16]. Intellectual disability in children with ASD which was initially thought to be as high as $75 \%$, currently seems to be much lesser at $40-55 \%$ [17]. Prevalence of ASD in individuals diagnosed with intellectual disabilities is $19.8 \%$ [18].

There is paucity of Indian studies on prevalence of ASD among children diagnosed with ID and also the prevalence of behaviour problems in this population. Hence this study was conducted with the objectives to assess the prevalence of ASD in the intellectually disabled, as well as the associated comorbidity patterns.

\section{Aims \& objectives}

- To assess the prevalence of ASD among children referred for assessment of Intellectual Disability (ID).

- To assess the various behavioural \& medical problems and its correlates in children with ASD and ID

Study setting: University-affiliated department of Psychiatry in tertiary care General hospital catering to lower and middle SES.

Study design: Cross-sectional study

Study period: August 2013 to November 2013.

Sample selection: It was a purposive sampling comprising 150 participants ( 68 females, 82 males) aged 6 to 18 years with intellectual disability referred to the IDD clinic.

\section{Study tools}

- A semi-structured questionnaire with details of medical history. Parents were asked questions to know if the child has any of the following symptoms which are described to be common medical symptoms in children with ASD - diarrhoea, constipation, bloating, nausea/vomiting, abdominal pain, skin allergies, asthma, giddiness/fainting, seizures, recurrent headaches [21-22].

- Behaviour Problems Inventory (BPI) - It is an informant-based behaviour rating instrument to assess maladaptive behaviours in persons with intellectual and developmental disabilities (IDD), including autism spectrum disorder (ASD). BPI was quantified based on the frequency of problem behaviours as indicated in the scale A-F being respectively taken as 0-5 and severity taken as 0-3. As we wanted to study severity, we used severity scores for analysis.

- Indian Scale for Assessment of Autism (ISAA) -for assessment of disability in ASD. It has 40 items divided under six domains, each item being rated in increasing severity of 1 to 5 . A score of $<70$ indicates no autism, 70-106 (mild autism), 107-153 (moderate autism), and >153 (severe autism).

\section{METHODOLOGY}

IQ assessment was done on the 150 study participants using Binet Kamat Test of intelligence if the child was verbal /Vineland Social Maturity Scale if child could not be interviewed. 122 children qualifying with mild \& moderate intellectual disability were screened for Autism Spectrum Disorders (ASD) using the ISAA (Indian Scale for Assessment of Autism) after informed consent from parents. Those with severe and profound IDD were excluded from the study as symptom presentations overlap with ASD and would necessitate detailed clinical assessment.

Socio-demographic details including semi-structured questionnaire to look into medical history was administered. Behavioural problems were assessed using Behaviour Problems Inventory (BPI). BPI severity score of 1-3 were analysed. Obtained data was analysed using appropriate statistical tests. Results obtained was compared with previous studies and conclusions were drawn. 


\section{RESULTS}

Prevalence of autism spectrum disorders in subjects with mild \& moderate intellectually disability was $16.39 \%(n=20)$.

Table 1: Socio-demographic profile

\begin{tabular}{|c|c|c|c|}
\hline & $\begin{array}{c}\text { Children with ASD } \\
\mathbf{( 2 0 )} \\
\text { Mean(SD) }\end{array}$ & $\begin{array}{c}\text { Children without } \\
\text { ASD(n=112) } \\
\text { Mean(SD) }\end{array}$ & t/chi sq (p value) \\
\hline Age in years & $7.86(1.34)$ & $9.72(2.45)$ & $3.30\left(0.0012^{*}\right)$ \\
\hline Urban background & 12 & 85 & $1.46(0.2)$ \\
\hline $\begin{array}{c}\text { Receiving special } \\
\text { education }\end{array}$ & 14 & 98 & $2.7(0.09)$ \\
\hline Income of parents(rs) & $12545(3456)$ & $18798(4387)$ & $6.04\left(0.001^{*}\right)$ \\
\hline Children on medication & 09 & 45 & $0.1(0.65)$ \\
\hline
\end{tabular}

Note - Children with ASD were significantly younger and their parents had less mean income than those without ASD.

Table 2: Medical symptoms and comorbidities in children with and without ASD

\begin{tabular}{|c|c|c|c|}
\hline & $\begin{array}{c}\text { Children with } \\
\text { ASD(20) }\end{array}$ & $\begin{array}{c}\text { Children without } \\
\text { ASD(n=112) }\end{array}$ & chi sq (p value) \\
\hline Diarrhea & 3 & 12 & $0.03(0.86)$ \\
\hline Constipation & 6 & 6 & $9.66\left(0.001^{*}\right)$ \\
\hline Bloating & 5 & 8 & $4.29\left(0.03^{*}\right)$ \\
\hline Nausea/Vomitting & 2 & 5 & $0.22(0.63)$ \\
\hline Abdominal pain & 7 & 15 & $4.25\left(0.03^{*}\right)$ \\
\hline Skin allergies & 4 & 18 & $0.01(0.91)$ \\
\hline Asthma & 1 & 5 & $0.01(0.91)$ \\
\hline Giddiness/fainting & 2 & 3 & $0.89(0.34)$ \\
\hline Seizures & 8 & 12 & $9.15\left(0.002^{*}\right)$ \\
\hline Recurrent headaches & 2 & 5 & $0.22(0.63)$ \\
\hline
\end{tabular}

Note - Children with ASD significantly had higher gastrointestinal symptoms such as constipation, bloating, abdominal pain. Also, they had higher seizure history than those without ASD.

Table 3: Mean scale scores among those with and without ASD

\begin{tabular}{|c|c|c|c|}
\hline & $\begin{array}{c}\text { Children with } \\
\text { ASD(20) } \\
\text { Mean(SD) }\end{array}$ & $\begin{array}{c}\text { Children without } \\
\text { ASD(n=112) } \\
\text { Mean(SD) }\end{array}$ & t(p value) \\
\hline IQ scores & $47.05(8.72)$ & $56.97(4.56)$ & $7.60\left(0.0001^{*}\right)$ \\
\hline ISAA scores & $112.85(8.90)$ & $65.80(8.82)$ & $21.94\left(0.0001^{*}\right)$ \\
\hline BPI- Total severity & $87.65(11.23)$ & $72.23(9.08)$ & $15.42\left(0.001^{*}\right)$ \\
\hline $\begin{array}{c}\text {-Self injurious } \\
\text { behaviour }\end{array}$ & $29.8(4.65)$ & $21.34(6.68)$ & $5.42\left(0.001^{*}\right)$ \\
\hline Stereotyped behaviour & $33.34(3.87)$ & $31.85(2.33)$ & $2.34\left(0.02^{\star}\right)$ \\
\hline Aggressive behavior & $17.63(2.11)$ & $12.24(5.33)$ & $4.44\left(0.001^{*}\right)$ \\
\hline
\end{tabular}

Note - Children with ASD had lower IQ scores, higher ISAA scores (which were in the mild range), higher total behaviour problems as well as self-injurious behaviour, stereotyped behaviour and aggressive behaviour scores.

\section{DISCUSSION}

Prevalence of autism spectrum disorders in those referred for Intellectual Disability was $16.39 \%$. This is in concordance with existing literature which cites a prevalence of 15-20\% of ASD among children with IDD. However, these studies have used Childhood Autism rating scale and Aberrant behaviour checklist for diagnosis of ASD and behaviour problems. We have used ISAA and BPI which are Indian based 
Table 4: Comparison of behavioural problems among mild and moderate autism groups

\begin{tabular}{|l|c|c|}
\hline & ISAA (Autism) Mild & ISAA (Autism) Moderate \\
\hline Mean BPI Scores & 51.00 & 87.22 \\
\hline \multicolumn{1}{|c|}{ SD } & 16.26 & 20.08 \\
\hline (n) & 7 & 13 \\
\hline p-value & $\mathbf{0 . 0 0 4 9 *}^{*}$ & \multicolumn{2}{|l}{} \\
\hline
\end{tabular}

Note - Children with moderate Autism significantly had higher behaviour problems than those with mild autism.

Table 5: Comparison of Autism scores among mild Vs moderate intellectual disability groups

\begin{tabular}{|c|c|c|}
\hline & Mild intellectual disability & Moderate intellectual disability \\
\hline $\begin{array}{l}\text { Mean autism } \\
\text { Score (ISAA) }\end{array}$ & 102.83 & 117 \\
\hline SD & 15.99 & 26.62 \\
\hline (n) & 8 & 12 \\
\hline p-value & \multicolumn{2}{|c|}{0.2658} \\
\hline
\end{tabular}

Note - There was no significant difference seen in autism scores among mild and moderate ID groups.

assessments and scales free to use respectively [18]. Children with ASD were of significantly lesser age in our study. This could probably be explained by the fact fact that children with comorbid ASD and ID tend to have more severe dysfunction and thus may come to clinical attention at an younger age than those without ASD. Children with ASD had higher prevalence of GI symptoms like constipation, bloating, abdominal pain than those without ASD. This is in line with available literature which states that gastrointestinal symptoms are described in $9-54 \%$ of autistic children among which constipation, diarrhea and abdominal distension are common symptoms. Histologic examination has also revealed reflex gastritis, chronic gastritis, duodenitis and cryptitis among these children which causes lower digestive enzyme activity leading to these symptoms [19-21].

Seizure disorder was associated with $30 \%$ of our sample, all of whom had moderate autism according to ISAA (none had Mild Autism), which is in accordance with previous studies which report prevalence estimates of epilepsy in children with autism ranging from $4 \%$ to $38 \%$. It is also described that the cooccurrence of epilepsy was associated with increasing child age, female gender, intellectual disability, speech problems and lower socioeconomic status [22].

There is evidence to say common genetic variants link gastrointestinal abnormalities with ASD. Immune dysfunction is associated with these gastrointestinal abnormalities which trigger seizures and autonomic dysfunction [23]. It is important to recognise this association and assess medical symptoms as these can be associated with behaviour symptoms in these children with ASD.

Children with ASD tended to have lower IQ scores and higher behavioural problems as evidenced by higher scores in total behavioural problems as well as stereotyped behaviour, aggression, and self-injurious behaviour. This is in line with existing literature which describes children with ASD having ID to have higher behaviour problems such as self-injurious behaviours, unusual fear responses, and eating abnormalities which increases with higher the degree of cognitive impairment [24].

Individuals with Moderate Autism had more behavioural problems than those with Mild Autism which was statistically significant. Studies have indicated that Autism severity is associated with behaviour problems with more severe ASD having severe behaviour problems [25].

There was no significant difference in autism scores among mild and moderate intellectually disabled children. However, we need to note that measuring intellectual disability in children with ASD becomes difficult because these children tend to have language impairment, show variability in performance in 
various domains of intelligence and most of the tests used to measure IQ measure verbal intelligence. Intelligence also does not indicate functioning in ASD. In this study, we still measured IQ since the children were referred to our department for IQ assessment.

\section{Limitations}

Cross sectional study design with purposive sampling.

Performance based IQ tests like Ravens progressive matrices which better measures IQ in ASD were not used.

\section{CONCLUSION}

This study indicates a notable prevalence of ASD among those with intellectual disability of about $20 \%$. These children have higher prevalence of medical issues like GI disturbances and seizures. They also have higher behavioural problems which tend to increase with the severity of autism.

\section{Implications}

There is preliminary evidence for the association between ASD, medical issues and behavioural problems. Available literature points toward a possible etiological association between the above. Knowing more about this association has significant implications on the overall management of these children. Hence, more studies which are methodologically robust need to be conducted to be conducted to study this association in future.

\section{REFERENCES}

1. American Psychiatric Association. Diagnostic and statistical manual of mental disorders (5th ed.). Arlington, VA: American Psychiatric Publishing; 2013.

2. Vivanti G, Barabaro J, Dissanayakke C, et al. Intellectual development in autism spectrum disorders: New insights from longitudinal studies. Front Hum Neurosci 2013;7:354.

3. Chakrabarti S, Fombonne E. Pervasive developmental disorders in preschool children. JAMA 2001;285(24): 3093-9.

4. Sappok T, Bergmann T, Kaiser H, et al. Autism in adults with mental retardation. Der Nervenarzt 2010;81: $1333-45$.

5. Autism Developmental Disabilities Monitoring Network (ADDM). Prevalence of autism spectrum disorders: Autism and developmental disabilities monitoring network, 14 sites, United States, 2002. Morbidity and Mortality Weekly Report. 2007;56(SS-1):12-28.

6. Baird G, Charman T, Baron-Cohen S, Cox A, Swettenham J, Wheelwright S, et al. A screening instrument for autism at 18 months of age: A 6-year follow-up study. J Am Acad Child Adolesc Psychiatry 2000;39:694-702.

7. Bertrand J, Mars A, Boyle C, Bove F, Yeargin-Allsopp M, Decoufle P. Prevalence of autism in a United States population: The brick township, New Jersey, investigation. Pediatrics 2001;108:1155-61.

8. Chakrabarti S, Fombonne E. Pervasive developmental disorders in preschool children. JAMA 2001;285:30939.

9. Chakrabarti S, Fombonne E. Pervasive developmental disorders in preschool children: Confirmation of high prevalence. Am J Psychiatry 2005;162:1133-41.

10. Charman T, Pickles A, Simonoff E, et al. IQ in children with autism spectrum disorders: Data from the Special Needs and Autism Project (SNAP). Psychol Med 2011;41:619-27.

11. Fombonne E. Epidemiological Investigations for Autism and Pervasive Developmental Disorders. In C. Lord (Ed.), Educating children with Autism. Washington, DC: National Academy of Sciences Press; 2001.

12. Fombonne E. Epidemiological surveys of autism and other pervasive developmental disorders: An update. J Autism Dev Disord 2003;33:365-82.

13. Goin-Kochel RP, Peters SU, Treadwell-Deering D. Parental reports on the prevalence of co-occurring intellectual disability among children with autism spectrum disorders. Res Autism Spectr Disord 2008;2:54656.

14. Yeargin-Allsopp M, Rice C, Karapurkar T, et al. Prevalence of autism in a US metropolitan area. JAMA 2003;289:49-55.

15. Action For Autism India, 2012. www.autism-india.org/

16. Centre for disease control and prevention; http://www.cdc.gov/mentalhealth/ 
17. Dawson $\mathrm{M}$ et al. Research Report The Level and Nature of Autistic Intelligence. Association for Psychological Science. 2007.

18. Vivian, Gillberg.C, ASD in children with physical or mental disability. Dev Med Child Neurol 1996;38(4):297313.

19. Horvath K, Papadimitriou J, Rabsztyn A, Drachenberg C, Tildon J. Gastrointestinal abnormalities in children with autistic disorder. J Pediatr 1999;135:559-63.

20. Horvath K, Perman JA. Autistic disorder and gastrointestinal disease. Curr Opin Pediatr 2002;14:583-7.

21. Wasilewska J, Jarocka-Cyrta E, Kaczmarski M. Gastrointestinal abnormalities in children with autism. Pol Merkur Lekarski 2009;27(157):40-3.

22. Thomas S, Hovinga ME, Rai D, et al. Brief Report: Prevalence of Co-occurring Epilepsy and Autism Spectrum Disorder: The U.S. National Survey of Children's Health 2011-2012. J Autism Dev Disord 2017;47(1):224-9.

23. Wasilewska, J., \& Klukowski, M. Gastrointestinal symptoms and autism spectrum disorder: links and risks a possible new overlap syndrome. Pediatr Health Med Ther 2015;6:153-66.

24. Murzius-Spencer M, Pettygrove S, Christensen D, Pedersen AL, Cunniff C, Meaney FJ et al. Behavioral problems in children with autism spectrum disorder with and without co-occurring intellectual disability. Res Autism Spectr Disord 2018;12(56):61-71.

25. Lindor E, Sivaratnam C, May T, Stefanac N, Howell K, Rinehart N. Problem Behavior in Autism Spectrum Disorder: Considering Core Symptom Severity and Accompanying Sleep Disturbance. Front Psychiatry $2019 ; 10,487$.

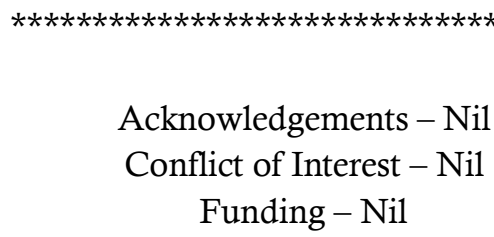

